\title{
Asphalt Pavement Structural Health Monitoring Utilizing FBG Sensors
}

$$
\text { Zejiao Dong }{ }^{1, a} \text {, Shenglong } \mathrm{Li}^{2, \mathrm{~b}} \text {, Jiayu Wen }{ }^{3, \mathrm{c}}, \text { Hongchun Chen }{ }^{4, d}
$$

${ }^{1}$ School of Transportation Science \& Engineering, Harbin Institute of Technology, Harbin 150090, China

${ }^{2}$ School of Transportation Science \& Engineering, Harbin Institute of Technology, Harbin 150090, China

${ }^{3}$ School of Transportation Science \& Engineering, Harbin Institute of Technology, Harbin 150090, China

${ }^{4}$ School of Transportation Science \& Engineering, Harbin Institute of Technology, Harbin 150090, China

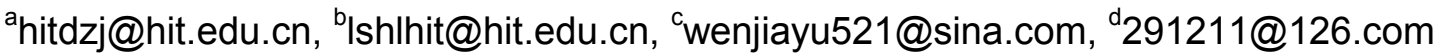

\section{Keywords: Asphalt pavement; long-term monitoring; SHM; FBG sensors}

\begin{abstract}
Assessment of pavement working state and service life is really meaningful for traffic security, design evaluation and road maintenance. However, this job seems to be a mission impossible, because it is unimaginable to learn exactly how a pavement works inside when the construction is finished. As a result, in this paper, current situation of pavement-design theory and testing methods was summarized, and at the same time the concept of Pavement Structural Health Monitoring (PSHM) was introduced, followed by the explanation of the FBG sensing component's basic theory. Then, an engineering application of utilizing FBG sensors in actual pavement was introduced, the monitoring effect was shown. Conclusions were that PSHM was of great importance and utilizing FBG sensors in PSHM was effective.
\end{abstract}

\section{Introduction}

Layered elastic system theory is the basic theroy in pavement design in China. Tensile stress of asphalt layer bottom, fatigue, and deflection are evalutaion indexes. Conventional survey and investigation methods adopted by researchers are core drilling, pavement cutting, Benkelman beam, FWD, automatic deflectometer, surface-curvature apparatus and etc. They are either destructive or with low-precision or low-frequency, and most important is that all of these methods are discontinuous and short-term. Long-term exposed in natural environment, pavement is deteriorating at the coupling effect of load, temperature, water and ultraviolet. It is difficult to veritably understand the mechanical response of pavement structure in actual environment by regular methods $[1,2]$.

Pavement condition has direct influence on traffic security, operating expenses, riding comfort and economic results in society. With the rapid development of the vehicle manufacturing technologies and cargo transporting demands, more and more heavy-duty asphalt pavements with superior performances have been constructed. Meanwhile, strain of the asphalt pavement will result in the destruction of pavement structure when it extends large enough. It is becoming a more and more outstanding problem, and adverse effects are following on.

Taking all the conditions having been illustrated above into consideration, necessity to monitor the service state of a pavement throughout its lifetime is apparently essential. Therefore, a new concept of asphalt pavement researching method has been put forward, that is PSHM. PSHM is a kind of advanced researching method which is a long-term and real-time process. The most common approach to PSHM is installing some sensors, including transverse strain sensors, vertical strain sensors, temperature sensors, and pressure cells, acquiring useful data and calculating them into 
helpful parameters like strain, stress and temperature. In this way, pavement structural mechanical response can be veritably understood via embedded sensors within pavement structure. Hence, the performance and category of sensors being used in monitoring becomes the key point to the success.

\section{FBG sensor}

The past 20 years has witnessed the rapid growth of optical fiber sensing technology. FBG sensors, as one of optical fiber components, have been widely applied in sensing fields, such as strain sensors and temperature sensors [3]. Compared with conventional sensors, FBG sensors are the most promising candidates to effectively replace conventional strain gauges for long-term monitoring applications in harsh circumstances [4]. They exhibit several advantages such as, flexibility, embeddability, high frequency, EMI immunity and many other obvious advantages, showing in Table 1. In Table 1, M stands for medium, L for low, Y for yes, E for excellent, G stands for good, $\mathrm{H}$ for high, $\mathrm{W}$ for wide and $\mathrm{N}$ for narrow.

Table 1 Performance Index of Sensing Components

\begin{tabular}{|c|c|c|c|c|c|c|}
\hline \multirow[b]{2}{*}{ Index } & \multicolumn{6}{|c|}{ Materials and Sensing Components } \\
\hline & $F B G$ & $\begin{array}{c}\text { Shape- } \\
\text { Remembering } \\
\text { Alloy }\end{array}$ & $\begin{array}{c}\text { Piezoelectric } \\
\text { Component }\end{array}$ & $\begin{array}{c}\text { Resistance } \\
\text { Strain } \\
\text { Gauge }\end{array}$ & $\begin{array}{c}\text { Carbon } \\
\text { Fiber }\end{array}$ & $\begin{array}{c}\text { Semi- } \\
\text { Conductor }\end{array}$ \\
\hline Price & M & M & M & $\mathrm{L}$ & $\mathrm{L}$ & M \\
\hline Distribution & Y & $\mathrm{Y}$ & $\mathrm{Y}$ & $\mathrm{Y}$ & $\mathrm{Y}$ & Y \\
\hline Compatibility & $\mathrm{E}$ & $\mathrm{E}$ & $\mathrm{E}$ & M & $\mathrm{E}$ & G \\
\hline Linearization & $\mathrm{E}$ & G & $\mathrm{E}$ & $\mathrm{E}$ & G & $\mathrm{E}$ \\
\hline Sensitivity & $\mathrm{H}$ & $\mathrm{H}$ & $\mathrm{H}$ & M & M & $\mathrm{H}$ \\
\hline $\begin{array}{c}\text { Deformation } \\
\text { Capacity }\end{array}$ & $\mathrm{E}$ & $\mathrm{E}$ & $\mathrm{E}$ & $\mathrm{E}$ & G & G \\
\hline Stability & $\mathrm{E}$ & G & $\mathrm{E}$ & G & $\mathrm{E}$ & $\mathrm{E}$ \\
\hline Endurance & $\mathrm{E}$ & M & $\mathrm{G}$ & $\mathrm{M}$ & $\mathrm{M}$ & $\mathrm{E}$ \\
\hline $\begin{array}{c}\text { Bandwidth of } \\
\text { Response } \\
\text { Frequency }\end{array}$ & W & $\mathrm{N}$ & W & $\mathrm{N}$ & W & W \\
\hline
\end{tabular}

The basic structure of fiber includes core, cladding, coating, reinforced fiber and protective material. Core and Cladding are the principal part of the fiber with the diameter $125 \mu \mathrm{m}$ which play a key role in transmitting the light. While others, such as coating, reinforced fiber and protective material, isolate interferential light and protect fiber.

The basic principle of a FBG sensor is to monitor the wavelength shift of the returned Bragg signal as a function of the measurement (e.g. strain, temperature or force). The Bragg wavelength of grating can be expressed as:

$$
\lambda_{B}=2 n_{\text {eff }} \Lambda \text {. }
$$

Where:

$\mathrm{n}_{\mathrm{eff}}=$ the effective refractive index and

$\Lambda=$ grating period. 
As shown in Eq. 1, the Bragg wavelength of fixating is related to the effective refractive index and grating period. Any physical process, which changes the effective refractive index and grating period, will induce the shift of Bragg wavelength of grating. The variation of Bragg wavelength of grating can be obtained as follows if a strain is applied on the fiber:

$$
\Delta \lambda_{B}=\lambda_{B} \times\left(\frac{\partial \Lambda}{\Lambda} / \frac{\partial l}{l}+\frac{d n_{e f f}}{n_{e f f}} / \frac{\partial l}{l}\right) \times \frac{\Delta l}{l} .
$$

Where:

$l=$ grating length and

$\Delta l=$ variation of fixating length .

As well as being sensitive to strain, the wavelength is also sensitive to temperature. The change of Bragg wavelength can be written as:

$$
\Delta \lambda_{B}=\alpha_{T} \cdot \Delta T \cdot \lambda_{B}
$$

Where:

$\alpha_{\mathrm{T}}=$ temperature sensitivity parameter of Bragg grating and

$\Delta \mathrm{T}=$ temperature variation relative to calibration temperature.

As a result, the relative shift in the Bragg wavelength due to an applied strain and a change in temperature can be expressed by:

$$
\Delta \lambda_{B}=\lambda_{B} \times\left(\frac{\partial \Lambda}{\Lambda} / \frac{\partial l}{l}+\frac{d n_{e f f}}{n_{e f f}} / \frac{\partial l}{l}\right) \times \frac{\Delta l}{l}+\alpha_{T} \cdot \Delta T \cdot \lambda_{B} .
$$

\section{Application of FBG sensor monitoring}

\section{Project design}

The main idea for the project is to measure the vertical compressive strain at the top of subgrade, the transverse tensile strain at the bottom of aspalt layer and the vertical compressive strain at the middle of asphalt layer based on key mechanical information and position in flexible pavement[5], which can be seen in Table 2. Aiming at the approach of perpetual pavement constructing in Jilin, considering the different utilities of different sensors, other than strain gauges, a temperature sensor was also installed, given as Fig. 1. Then a final installation plan was settled, given in Table 4. We choosed Tider-FBG-LFRP as transverse strain gauge and Tider-FBG-SFRP as vertical strain gauge. Parameters of these two series of sensors are shown in Table 3.

Table 2 Key Mechanical Information and Position within Flexible Pavement Structure

\begin{tabular}{c|c|c}
\hline Failure Types & Mechanical Information & Key Position \\
\hline Fatigue Cracking & $\begin{array}{c}\text { Transverse tensile } \\
\text { strain/stress }\end{array}$ & Top/Bottom of asphalt layer \\
\hline $\begin{array}{c}\text { Permanent Deformation of } \\
\text { Surface Layer }\end{array}$ & $\begin{array}{c}\text { Vertical compressive } \\
\text { strain/stress }\end{array}$ & Middle of asphalt layer \\
\hline $\begin{array}{c}\text { Permanent Deformation of } \\
\text { Base Layer }\end{array}$ & $\begin{array}{c}\text { Vertical compressive } \\
\text { strain/stress }\end{array}$ & Base layer \\
\hline $\begin{array}{c}\text { Permanent Deformation of } \\
\text { Subgrade }\end{array}$ & $\begin{array}{c}\text { Vertical compressive } \\
\text { strain/stress }\end{array}$ & Top of subgrade \\
\hline
\end{tabular}




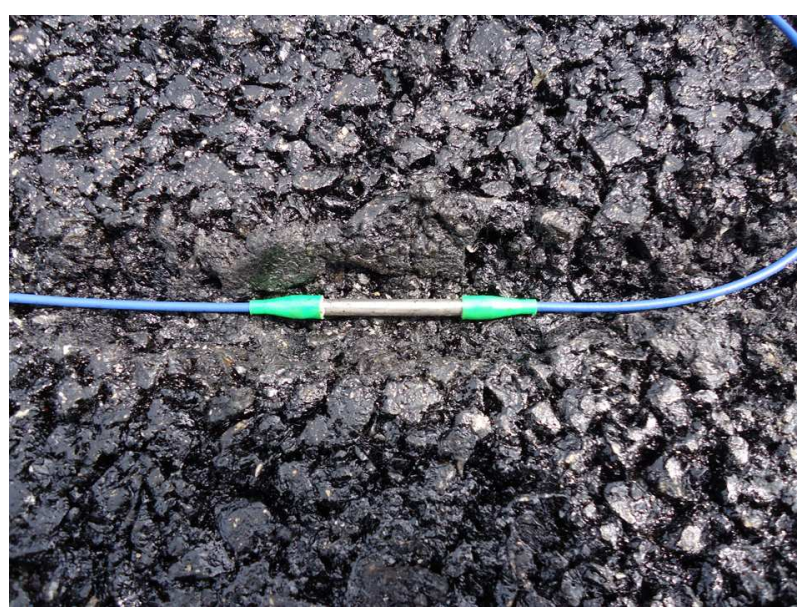

Fig. 1 Temperature sensor

Table 3 Parameters of FBG Sensors

\begin{tabular}{l|c|c|c|c|c|c}
\hline Parameters & $\begin{array}{c}\text { Expanding } \\
\text { Diameter } \\
{[\mathrm{mm}]}\end{array}$ & $\begin{array}{c}\text { Packing } \\
\text { Diameter }[\mathrm{mm}]\end{array}$ & $\begin{array}{c}\text { Length } \\
{[\mathrm{mm}]}\end{array}$ & $\begin{array}{c}\text { Elastic } \\
\text { Module } \\
{[\mathrm{GPa}]}\end{array}$ & $\begin{array}{c}\text { Range } \\
{[\mu \varepsilon]}\end{array}$ & $\begin{array}{c}\text { Sensitivity } \\
\text { Coefficient } \\
{[\mathrm{pm} / \mu \varepsilon]}\end{array}$ \\
\hline LFRP Series & 20 & 4 & 70 & 50 & \pm 5000 & 1.2 \\
\hline SFRP Series & 20 & 6 & 20 & 50 & \pm 5000 & 1.2 \\
\hline
\end{tabular}

Table 4 Pavement Structural Information and Installation Position

\begin{tabular}{c|c|c|c}
\hline Material & Thickness & Installation Position & Type of Sensor \\
\hline SMA-16 & $5 \mathrm{~cm}$ & Bottom & Temperature \\
\hline$A C-20$ & $7 \mathrm{~cm}$ & Bottom & Vertical strain sensor \\
\hline$A C-25$ & $10 \mathrm{~cm}$ & -- & -- \\
\hline ATB-30 & $12 \mathrm{~cm}$ & Bottom & Transverse strain sensor \\
\hline Granular Base & $20 \mathrm{~cm}$ & -- & -- \\
\hline Subgrade & -- & Top & Vertical strain sensor \\
\hline
\end{tabular}

\section{Sensor installation}

In order to obtain accurate results, precise and cautious installation is necessary. Several steps as follows should be specially drawn attention to.

First, aclinic installation. To ensure the veracity of measurement, strain distraction must be eliminated. That means we have to level the surface where we set gauge, as Fig. 2(a) shows.

Second, cable binding. Given as Fig. 3. To avoid loss of signal for being pulled up, cables must be bound. According to NCAT's testing resulting, sensors' survive rate of which whose cables were bound was far higher than not[6]. When all of sensors in single layer had been installed, all cables should be bound together in the end, as Fig. 2(b) shows. We also can get a full view of sensor installation from Fig. 2(b).

Third, static compaction. When aspalt mixture was just being paved, there is not too much intensity in pavement to protect sensors from heavy duty. Therefore, the pavement should be compacted without vibration during first two times, as Fig. 4 shows. 


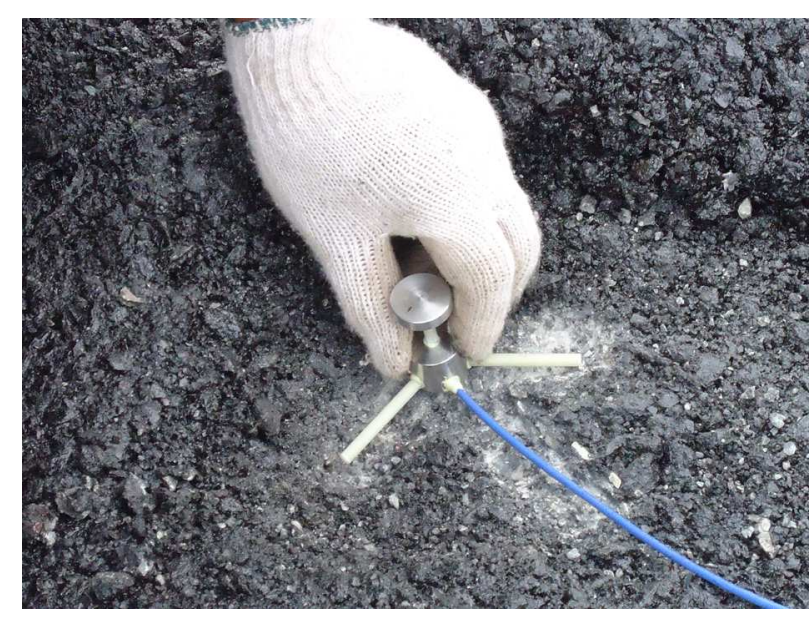

(a) Vertical strain sensor

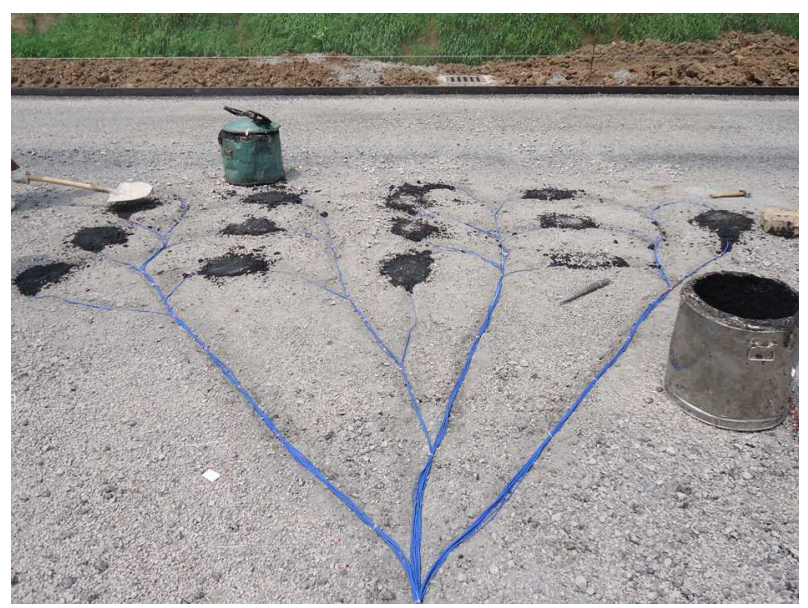

(b) Full view of installation

Fig. 2 Installation of FBG sensors

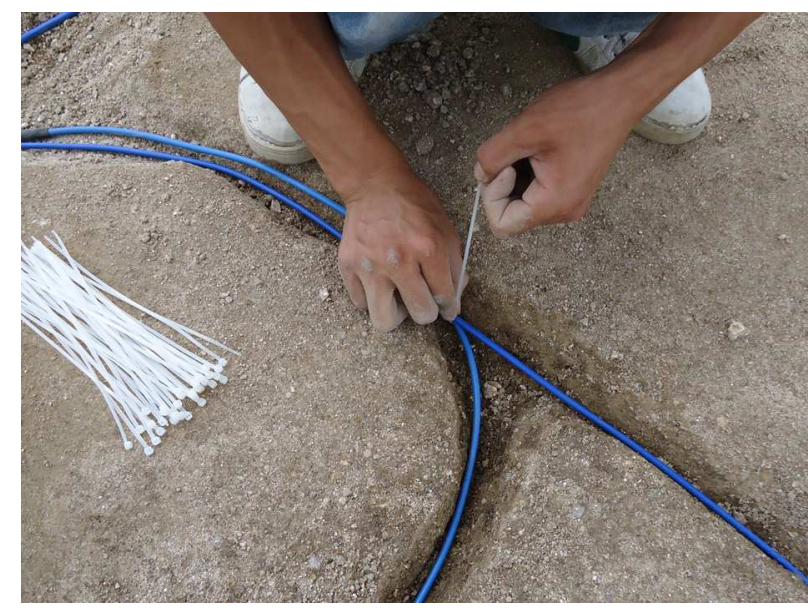

Fig. 3 Cable binding

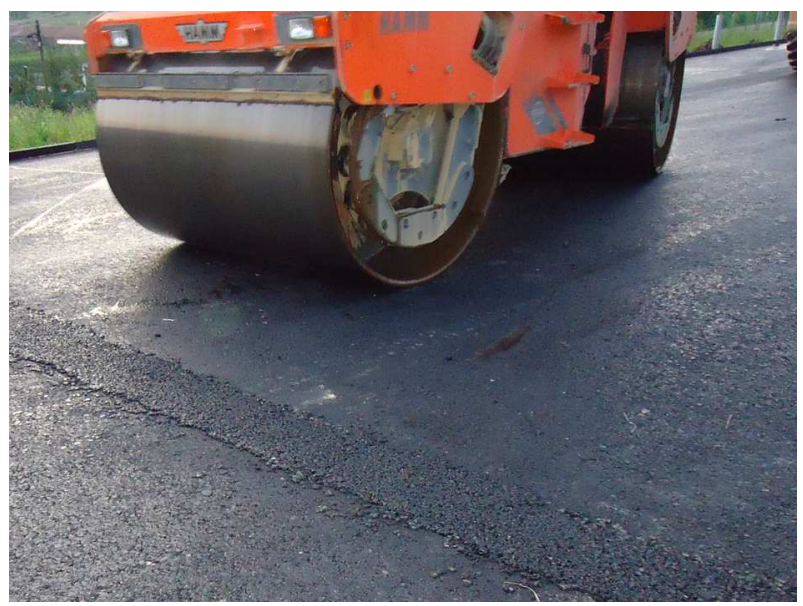

Fig. 4 Static compaction

\section{Data acquisition}

In this project, the FBG interrogator is TFBGD-9000 from Tider Co Ltd, China, with resolution of $1 \mathrm{pm}$, frequency of $300 \mathrm{~Hz}$, shown in Fig. 5. By comparatively long-term data acquiring and calculating, we got a temperature-time curve and some strain-time curves, given as Fig. 6, Fig. 7 and Fig. 8. From the temperature-time curve, we learn that how the pavement temperature changes in one day in May in Jilin. From strain-time curves, we exactly understand that how much the strain is at some certain points within the pavement. There is an issue should be explained, that is Fig. 7 and Fig. 8 are not the responses of the same vehicle.

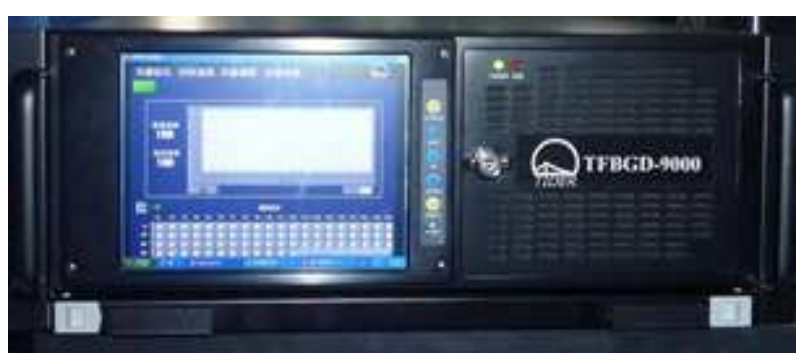

Fig. 5 TFBGD-9000 interrogator

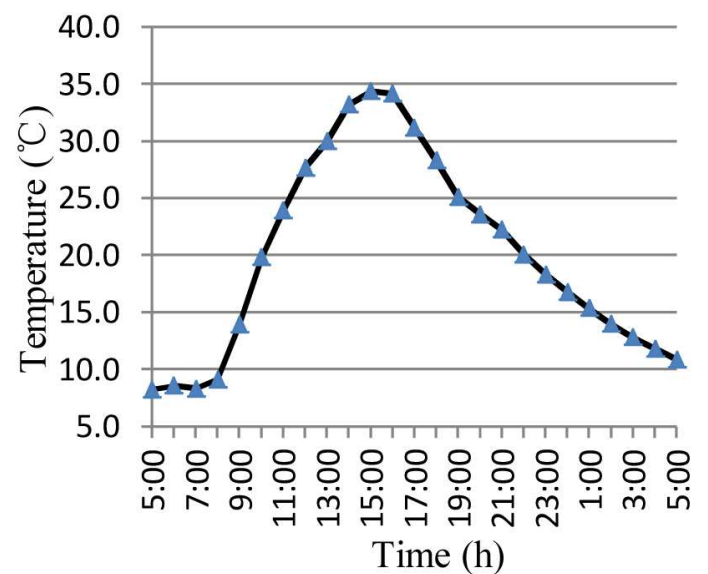

Fig. 6 Temperature of top layer 


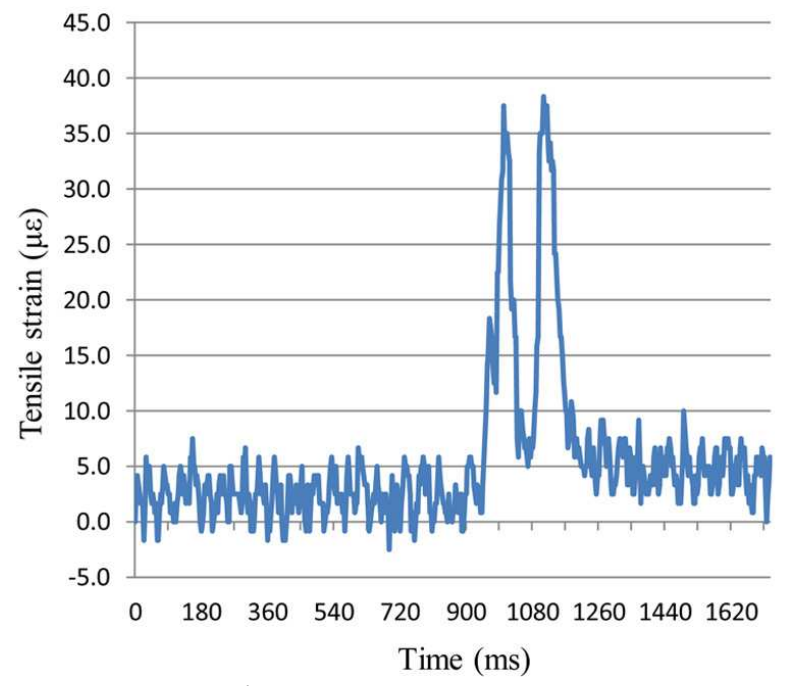

Fig. 7 Transverse sensor

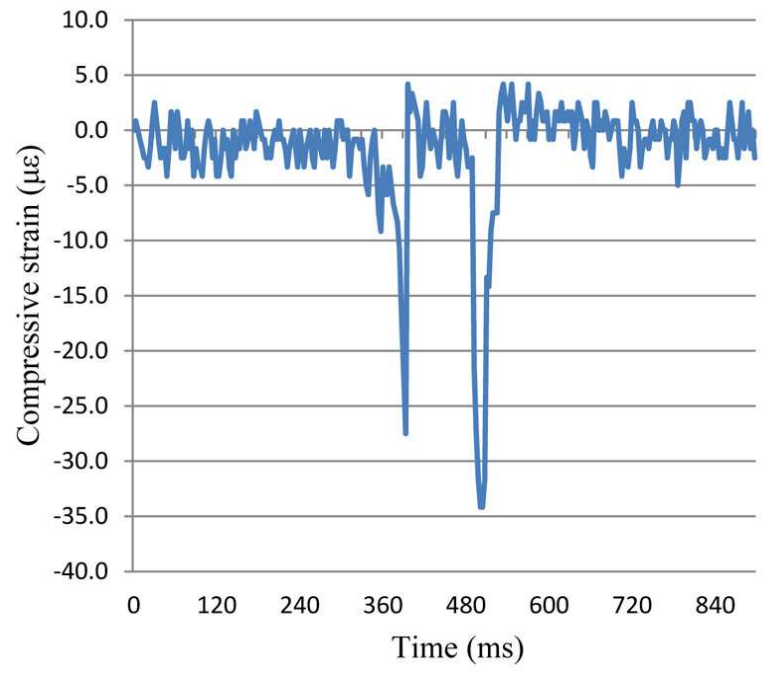

Fig. 8 Vertical sensor

\section{Conclusions}

The concept of Pavement Structural Health Monitoring was proposed in this paper. By analyzing conventional testing methods and results of application of FBG sensor monitoring, some key observations were:

1. By means of comparing with conventional pavement testing methods and effectiveness analysis, structural health monitoring is essentially necessary in pavement service lifetime, which brings a predominant researching method in highway field.

2. Using FBG sensors for strain and temperature monitoring in actual pavement, absolute temperature in a single day and dynamic response of a vehicle was obtained, good results were gained. This is a successful application of FBG sensor in pavement monitoring.

\section{References}

[1] Liu Shulong, Experimental Study on Monitoring Asphalt Pavement Performance Health Using Fiber Bragg Grating, Nanjing University of Aeronautics and Astronautics (2011).

[2] Li Chuanlin, Study on The Structure Test-Method of Asphalt Pavement Based on Internal Sensor Survey, Chang'an University, Xi'an, China (2008).

[3] Ren Liang, The Application of Fiber Bragg Grating Technology in Structure Health Monitoring, Dalian University of Technology (2008).

[4] X. F. Zhao, J. P. Ou, Long Sensing Gauge Fiber Bragg Grating Sensor with Pretension, J, ASCE (2003).

[5] Sun Zongjie, Initial Monitoring and Analysis on Dynamic Response of Pavement Structure, Harbin Institute of Technology (2011),pp:26-52.

[6] David H. Timm Angela L. Priest Thomas V. McEwen Design and Instrumentation of the Structural Pavement Experiment at the NCAT Test Track .NCAT Report 04-01 April 2004. 